Revista do SELL

v. 6 , no. 3

ISSN: $1983-3873$

\title{
PROPOSTA DE ENSINO DA CONDICIONALIDADE EXPRESSA PELO CONECTOR SE: UMA ABORDAGEM SOCIOLINGUÍSTICA
}

PROPOSAL FOR CONDICIONALITY TEACHING EXPRESSED BY THE CONNECTOR IF: A SOCIOLINGUISTIC APPROACH

\author{
Rosangela Rodrigues \\ Universidade Federal do Trinângulo Mineiro
}

\begin{abstract}
RESUMO: O artigo tem por objetivo analisar o tratamento dispensado pela gramática normativa em contraponto às gramaticas propostas pela sociolinguística varicionista sobre a condicionalidade expressa pelo conector SE. O presente trabalho busca investigar correlações entre aspectos formais da condicional SE no Português do Brasil e aspectos da interpretação dessas construções determinados contextualmente.

O que se propõe neste artigo é além de analisar o que prescrevem as gramáticas e as pesquisas, aproximar os conceitos da condicionalidade expressos pelo conector SE e evidenciar o seu uso em textos próximos ao aluno por meio de uma proposta de atividade que tem o objetivo de enfatizar a língua em uso e suas relações de sentido.
\end{abstract}

PALAVRAS-CHAVE: Construções condicionais; Conector SE; Proposta de ensino.

ABSTRACT: The article aims to analyze the treatment of normative grammar in counterpoint to the grammar proposed by varicionista sociolinguistics on the conditionality expressed by the SE connector. The present work seeks to investigate correlations between formal aspects of the conditional SE in Brazilian Portuguese and aspects of the interpretation of these contextually determined constructs. The purpose of this article is to analyze grammar and research, to approximate the concepts of conditionality expressed by the SE connector, and to show its use in texts close to the student through a proposal of activity that aims to Emphasize the language in use and its relations of meaning.

KEYWORDS: Conditional constructions; SE connector; Teaching proposal.

\section{INTRODUÇÃO}

A condicionalidade expressa pelo conector SE, em minha experiência docente, foi trabalhada quase que exclusivamente sobre a metalinguagem, ou seja, no estudo baseado nas gramáticas normativas que preconizam a língua de forma mecânica e teórica, sem consideração a um processo reflexivo do uso e da compreensão lingüística do texto. Ainda muito focado no ensino tradicional e presente nos livros didáticos utilizados em sala de aula para abordar o tópico sobre período composto por subordinação adverbial. Os quais trazem as classificações das orações, as conjunções de cada grupo, e, posteriormente, exercícios de fixação das nomenclaturas para a decoração dos nomes das orações de acordo com o conector. 


\section{Revista do SELL}

v. 6 , no. 3

ISSN: $1983-3873$

No entanto, é muito comum que, ao final do Ensino Fundamental II, o aluno não compreenda seu uso na leitura e na produção textual de textos diversos. Como professorapesquisadora, uma possibilidade de abordagem do tema em sala de aula será proposta: uma atividade didática voltada para 0 9ำ ano do ensino fundamental II que tem como objetivo aproximar os conceitos gramaticais de condicionalidade aos alunos de uma escola da periferia de Orlândia (SP) procurando enfatizar a língua em uso e as relações de sentido provocadas pela linguagem.

O professor que tem o livro didático como seu principal material de apoio, precisa se atentar para o que preconiza os PCNs, documento oficial do governo federal norteador do ensino, que defendem que o domínio da leitura e da escrita é o objetivo central do ensino de língua portuguesa. E ainda, mostra-se muito comprometido com o ensino das variações que compõem o português brasileiro, todavia, deixa lacunas quanto às concepções de norma e gramática.

Sendo assim, cabe ao professor oferecer condições para que os alunos reconheçam todas as possibilidades que a língua oferece. Desta forma, além de conhecerem a gramática normativa, aos alunos deveria ser apresentadas atividades com a gramática descritiva que considere também a gramática vernácula, aquela gramática que o indivíduo traz internalizada. Tudo isso com o objetivo de melhorar as habilidades de leitura e escrita dos aprendizes.

Por isso, na perspectiva da sociolinguística, o aprender, o estudar, e principalmente, o ensinar da língua exigem ações dinâmicas que direcionem o aluno a compreensão de que não somente pela gramática normativa se compreende a língua. Mas, apresentar outras possibilidades, que considerem a língua a partir de uma reflexão dos seus usos, bem como as variantes linguísticas, como oportunidade e objeto de estudo. Por isso, se considera a sociolinguística a perspectiva pedagógica deste estudo.

Diante do exposto, as contribuições da sociolinguística varicionista permite ampliar as possibilidades de estudo do tema, associados aos gramáticos da Linguística Funcional, como Perini (2010) e Neves (2011) abordaremos não somente a classificação tradicional das condicionais com o conector SE, mas se procurará evidenciar que a construção lexical ou sintática interfere na produção global de sentido do texto. Nas gramáticas tradicionais a relação é marcada pela classificação das conjunções de forma estática, como se somente tal conjunção carregasse todo o sentido das orações. No entanto, essa relação semântica não é percebida apenas pela marca dessa conjunção, como prescreve a tradição, já que no caso das condicionais, o modo verbal interferirá na interpretação semântico/pragmático. 


\section{Revista do SELL}

v. 6 , no. 3

ISSN: $1983-3873$

O estudo da condicionalidade no Português Brasileiro será tratado como uma categoria que expressa relações variadas conforme se combina com outras construções e/ou elementos dos diferenciados contextos. Portanto, não se pode analisar levando em consideração somente o conector, mas é importante investigar os aspectos relevantes à interpretação.

Finalmente, após as análises dos conceitos, propor-se-á uma atividade didática que tenha o objetivo de aproximar esses conceitos aos alunos. A atividade é voltada para o 9o ano do Ensino Fundamental II e procurará ajudar o aluno a perceber o uso dessa estrutura, além das relações semânticas estabelecidas nos textos.

\section{O QUE DIZEM AS GRAMÁTICAS TRADICIONAIS VERSUS A} SOCIOLINGUÍSTICA

A tradição no ensino de Língua Portuguesa baseia-se nas gramáticas normativas, aquelas que seguem a norma gramatical. Faraco (2008, p.81), esclarece-nos que a norma gramatical é aquela idealizada por filólogos renomados e transformada em manuais tradicionais, como gramáticas e dicionários, que contemplam "o conjunto de fenômenos apresentados como cultos/comuns/standard por esses gramáticos".

Porém, a língua que se observa na vivência social, na interação entre os sujeitos na sociedade apresenta variações que destoam da norma gramatical. Para Labov (In: Monteiro, 2000, p. 17), existe uma troca entre língua e sociedade, pois “(...) a própria língua como sistema acompanha de perto a evolução da sociedade e reflete de certo modo os padrões de comportamento, que variam em função do tempo e do espaço". Portanto, cabe ao professor em sala de aula, explorar a língua e suas transformações, analisando as variações que ocorrem no uso cotidiano, de acordo com os contextos de produção e recepção, considerando seus usos e o sentido global do texto.

As gramáticas normativas, aqui discutidas, Bechara (2009) e Cunha (2001), tratam as orações subordinadas adverbiais analisando sua função sintática, ou seja, sua estrutura frasal. E, nesta abordagem teórica, são unânimes quanto à fixação da classificação de uma oração pela marca da conjunção expressa na sentença que proporciona o enquadramento da mesma. Cunha (2001, p.587) define as orações subordinadas adverbiais condicionais, como 


\section{Revista do SELL}

v. 6 , no. 3

ISSN: $1983-3873$

Condicionais (iniciam uma oração subordinada em que se indica uma hipótese ou uma condição necessária para que seja realizado ou não o fato principal): se, caso, contanto que, salvo se, sem que [=se não], dado que, desde que, a menos que, a não ser que, etc.:

(1a) Se aquele entrasse, também os outros poderiam tentar...

(1b) ___ A entrevista ficou marcada para as quatro da tarde, caso você não prefira ir à noite.

Percebe-se que em (1a) a oração subordinada inicia a sentença, a qual exerce função sintática da oração principal, expressa no segundo segmento. Em (1b) a oração principal abre a sentença, seguida pela oração condicional que complementa sintaticamente a primeira parte dessa sentença.

Na mesma perspectiva, Bechara (2009, p. 327) postula que

Este modo de dizer é frequente nas argumentações. As principais conjunções condicionais são: se, caso, sem que, uma vez que (com verbo no subjuntivo), desde que (com verbo no subjuntivo), dado que, contanto que, etc:

(2a) Se os homens não tivessem alguma coisa de loucos, seriam incapazes de heroísmo.

(2b) Se as viagens simplesmente instruíssem os homens, os marinheiros seriam os mais instruídos.

Sob este enfoque, e observando outros estudos, pode-se perceber que as conjunções é que determinam, pela gramática normativa, a relação de condição. Observemos o quadro 1 , das conjunções condicionais nos períodos históricos do Português. 


\section{Revista do SELL}

v. 6 , no. 3

ISSN: $1983-3873$

\section{QUADRO 1}

Conjunções Condicionais

\begin{tabular}{l|l}
\hline & si (se) \\
& $n i s i$ (se não) \\
& $n i$ (se não) \\
& sin (se pelo contrário) \\
& modo (contanto que) \\
& dummodo (contanto que) \\
\hline & se \\
& se/salvo sse \\
& salvo que \\
Português arcaico & contanto que \\
(séc. XIII a séc. XV) & form que \\
& fora que \\
& fora se \\
& senon tanto se \\
& ergo \\
& marcar que \\
\hline & se \\
Português moderno & mais que \\
& que \\
\hline
\end{tabular}

Quadro 1 - Conjunções condicionais

Fonte: Barreto (1999, p. 45, v. III, adaptado)

Nas gramáticas classifica-se como condicionalidade as orações que apresentam determinadas conjunções, que para Bechara (2009, p. 327), são: "se, caso, sem que, uma vez que (com o verbo no subjuntivo), desde que (com o verbo no subjuntivo), dado que e contanto que." Mas, para este estudo, nos ateremos ao conector SE.

Semelhante à tradição normativista, o livro didático, classifica as orações conforme as conjunções. Veja a figura 1, abaixo:

\section{Condicionais}

|Follade S Fycto, das, 2013i

Expressam uma hipótese ou condiçào Oanüncio combate o uso de celular no trinsito A fraie 'Se vocé para que ocorra o fato expresso na oraçào omotorista comprovar que estáatentoanos perigos do trainsito principal:

\section{"Se eu quiser falar com Deus, tenho que ficar a s66"}

Sảo introduzidas pelas conjunçōes subordinativas condicionais se, caso, contanto que, desde que. salvo se, a menos que, sem que, etc

Figura 1 - A condicionalidade expressa pelas conjunções no livro didático.

Fonte: Cereja e Magalhães (2015, p. 81). 


\section{Revista do SELL}

v. 6 , no. 3

ISSN: $1983-3873$

\section{CONFRONTO ENTRE A GRAMÁTICA TRADICIONAL E OUTRAS} PERSPECTIVAS

Na prática docente, percebe-se que o ensino das construções condicionais, ainda está pautado somente ao estrutural. Os livros didáticos abordam a questão focando na presença do conector como elemento único de determinação do tipo de oração. Exercícios que buscam classificar as orações são feitos de forma mecânica, com análise em frases soltas e descontextualizadas, produzindo no aluno a obrigação de decorar tais classificações. Não se exploram os usos dos conectores e tampouco o porquê da diferenciação dos sentidos produzidos pelos usos em determinados contextos.

Assim sendo, as justificativas apresentadas pela gramática tradicional não respondem aos questionamentos sobre outros aspectos que não os estruturais de um texto. Diante disso, surgiram novos estudos que procuravam perceber não só as funções sintáticas da sentença condicional, mas também as funções semânticas e discursivopragmáticas destes itens da gramática.

Os gramáticos envolvidos neste estudo, Neves (2011) e Perini (2010), adotam a concepção de gramática descritiva-prescritiva, ou seja, aquela que faz descrição das estruturas e usos de uma língua, sem desprezar as orientações da gramática normativa.

Para Neves (2011, p. 13), "[a gramática] parte dos próprios itens lexicais e gramaticais da língua e, explicitando o seu uso em textos, vai compondo 'a gramática' desses itens, isto é, vai mostrando as regras que regem o seu funcionamento em todos os níveis, desde o sintagma até o texto".

Perini (2010) compartilha desta visão de estudo da gramática, e apresenta a condicionalidade expressa pela conjunção SE, num grupo separado e peculiar, distinguindo-o em quatro usos: a) se condicional, b) se contrafactual, c) se factivo, e d) se nominalizador.

A condicionalidade para Neves (2011, p. 829-835) são construções complexas que podem ser expressas pelas conjunções: se, caso, que, desde que, contanto que, uma vez que, a menos que, sem que, a não ser que, salvo se, exceto se. Tais construções podem ser dos subtipos: condicionais factuais/ reais, condicionais contrafactuais e condicionais eventuais/ potenciais. Ou seja, para o entendimento deste tipo de oração, a visão mais 


\section{Revista do SELL}

v. 6 , no. 3

ISSN: $1983-3873$

tradicional entende que a primeira oração deva ser verdadeira, bem como a oração condicionada também será verdadeira. Este tipo de construção designa condições numa relação lógico-semântica, cujo enunciado entende "p" como a primeira oração e "q" a segunda, e ambas como verdadeiras.

Além dos grupos descritos acima, Neves (2011) ainda esclarece que as orações condicionais antepostas, que são as mais frequentes, apresentam tópico discursivo que servirá de apoio à referência, como uma informação já anunciada.

Veja no exemplo:

Que no mundo eu conheço, todos só querem vantagem, só querem tirar de si. A força está com o dinheiro, palavra não vale nada, honra não paga comida. SE tudo está desse jeito, eu não posso confiar! (p. 834, grifo nosso).

Observa-se que os termos grifados, faz referência ao que já foi dito anteriormente, ou seja, é um tópico discursivo de retomada que encapsula uma informação já conhecida ou que não constitui uma novidade completa para o interlocutor.

E deste ponto em diante, ater-se-á a Perini (2010), que diferentemente da tradição gramatical reconhece quatro usos do SE condicional. Os quais serão considerados:

\section{SE condicional}

Nos estudos de Perini (2010), este tipo de uso da condicional ocorre com a conjunção SE associada à forma verbal em qualquer tempo do modo indicativo; ou no modo subjuntivo, com exceção do tempo no presente, somente nos tempos imperfeito ou futuro. A condição, nestes casos, atenderia a colocação da oração principal.

(3a) Se alguém precisa de ajuda, posso dar uma mãozinha (p. 284).

(3b) Vou ficar feliz se você fizer esse tratamento (p. 284).

\section{SE contrafactual}

Quando a conjunção SE é associada à forma verbal do imperfeito do subjuntivo, a condição, nestes casos, expressa uma sentença não verdadeira e improvável. Ou seja, o pressuposto da condição é algo irrealizável.

(4a) Se você fizesse esse tratamento, ficaria curado (p. 284).

(4b) Se eu tivesse uns dez mil sobrando, iria passar uns dias em Nova lorque (p. 284).

Observa-se que a conjunção SE pode vir no início da sentença, no meio da sentença ou na segunda oração. E ainda, que a co-ocorrência da conjunção SE com determinados modos e tempos verbais são importantes na construção semântico-pragmático diferenciando o sentido global do texto. 


\section{Revista do SELL}

v. 6 , no. 3

ISSN: $1983-3873$

\section{SE factivo}

Para o autor, neste tipo de uso, a expressão introduzida pela conjunção SE exprime um fato, com uma problemática já resolvida, mesmo que de maneira pressuposta. E neste caso, a forma verbal associada na construção é no modo indicativo.

(5a) Se você resolveu todos os seus problemas, por que continua reclamando? (p. 285).

(5b) Se a cidade é tão grande, não vai ser difícil encontrar um apartamento (p. 285).

\section{SE nominalizador}

No último uso apresentado por Perini, considera-se ainda, a introdução das interrogativas indiretas associadas à conjunção SE.

(6a) Ninguém sabe se essa cerveja presta (p. 285).

(6b) A Camila perguntou se o Sérgio estava em casa (p. 285).

Após os quatro usos da condicional, apresentados por Perini (2010), verifica-se que a construção da sentença é importante na análise do texto, mas que somente os elementos linguísticos presentes no co-texto, não são suficientes para a compreensão total do interlocutor. Uma vez que, é perceptível que alguns modos e formas verbais estão presentes em mais de um tipo de uso da conjunção SE. Por isso, enfatiza-se a necessidade de analisar o todo, pois uma conjunção ou conector, não possibilita, exclusivamente, um único sentido semântico, e esta variação pode estar fora do textual, no contexto - na situcionalidade do texto - como elemento de grande importância para a interpretação global do enunciado.

A gramática normativa utiliza-se do termo conjunções para falar da ligação entre orações subordinadas condicionais. Porém, esta denominação não é unanime entre os linguistas, uma vez que outros estudiosos usam o termo conector, como é o caso de Antunes (2014, p. 122) que define conector, como

algo que une ou liga, já se sobressaindo com isso a importante função desse grupo de palavras no estabelecimento da coesão e da coerência do texto. Trata-se, portanto, de um item que desempenha a grande função de marcar a conexão lógico-discursiva entre partes do texto, sejam essas partes orações, períodos, parágrafos ou blocos de parágrafos.

Cabe-nos esclarecer, que a preferência pelo termo conector é adotada, pois, tem-se a intenção de não se ater somente a propriedade de ligação atribuída a estes elementos linguísticos, mas às relações de natureza semântica que esses expressam. 


\section{Revista do SELL}

v. 6 , no. 3

ISSN: $1983-3873$

\section{PROPOSTA DE ATIVIDADE DIDÁTICA}

Nas escolas, geralmente, as aulas sobre conectores são muito próximas do que prega a gramática normativa, ou seja, estudam-se as conjunções coordenativas e subordinativas e sua aplicabilidade fica restrita a análise de um conjunto de frases criadas com o objetivo de classificá-las.

Antunes (2014, p. 124) acrescenta

E, como a escola não deixa aflorar a consciência de que esses exercícios retratam atividades reais de linguagem, a função dos conectores, na expressão de uma determinada relação semântica (de sentido, pois), não chega a ser percebida. O que se 'aprende' vale apenas para o dia dos testes[...].

Ao professor cabe o desafio de tornar o ensino dos conectores, e neste caso, da condicionalidade expressa pelo conector SE, em leituras significativas para a compreensão do sentido global do texto. Posto que, este aprendizado possa ser assimilado pelos alunos, e, posteriormente, desenvolvido em suas próprias escritas.

Sabe-se que ao professor, compete ainda, no seu fazer pedagógico, considerar a gramática interna dos alunos, aquele saber vernacular - saber social da língua. Como usuários da língua materna, temos um conjunto de regras internalizadas sobre 0 funcionamento da língua, que permite a todos falantes dar significados aos textos. Por isso, a escola precisa não só respeitar, mas também aprender a valorizar os conhecimentos linguísticos trazidos por seus aprendizes para dentro das salas de aulas. Portanto, conforme Antunes (2014, p. 131) "...qualquer ponto gramatical presente em um texto se expressa, justifica-se e se explica em submissão aos sentidos e intenções. A gramática é, pois, serva desses sentidos e intenções [...]".

Reconhece-se, como educador, que a língua precisa ser trabalhada na escola sob seus vários aspectos, deste modo, compartilha-se com os estudos sociolinguísticos de Barbosa (2011), de que os três saberes da gramática ${ }^{1}$ precisam estar presentes nas aulas

\footnotetext{
${ }^{1}$ Os estudos de Barbosa (2011) apontam três saberes envolvidos no ensino de Língua Portuguesa, a saber: a) saber linguístico vernacular: corresponde aquilo que é compartilhado no convívio social, ou seja, as normas que o indivíduo já traz internalizado; b) saber linguístico descritivo/ prescritivo: aquele conhecimento da gramática tradicional que segue o modelo greco-romano de gramática e; c) saber linguístico descritivo-teórico: conhecimento desenvolvido nas pesquisas acadêmicas de análise linguística.
} 


\section{Revista do SELL}

v. 6 , no. 3

ISSN: $1983-3873$

de linguagens. Portanto, o ensino centrado somente na gramática normativa não é capaz de responder aos fatores pragmáticos-semânticos da língua em uso.

Desta forma, no exemplo: "A senhora pediu? Nóis já fazia”.

O dizer acima, de uma aluna em sala de aula, no qual, não há marcação por conjunção, não seria classificado como condicional na gramática normativa. Mas, 0 professor, após interagir com a aluna, identifica a presença de um conector "SE" implícito. Pois, a fala expressa por ela corresponderia a "Se a senhora pedisse, nós já teríamos feito". Portanto, um caso de condicionalidade SE factiva, na qual o fato levantado pelo conector já é uma problemática pressupostamente resolvida.

Apresentar-se-á atividades (apêndice) como um caminho possível para o ensino da condicionalidade expressa pelo conector SE.

\subsection{DESCRIÇÃO DAS ATIVIDADES PROPOSTAS}

A primeira atividade propõe um trabalho com os alunos dos $9 .{ }^{\circ} \mathrm{s}$ anos, cuja letra de música servirá de pretexto. Para tanto, sugere-se a canção "Trem-bala" da cantora e compositora Ana Vilela, que é de Londrina/PR. Tal canção "viralizou" pela rede social Whatsapp em 2016, portanto, acredita-se ser um texto interessante para os alunos.

Após a introdução da canção e das reflexões de seus sentidos, conforme atividade disposta no apêndice A. O professor deve destacar o trecho da canção: “A gente não pode ter tudo/ Qual seria a graça do mundo se fosse assim/ Por isso eu prefiro sorrisos/ E os presentes que a vida trouxe/ Pra perto de mim". O exercício reflexivo tem a intenção de fazer com que os alunos percebam que o uso do verbo no pretérito do subjuntivo "fosse", afeta a relação de sentido do texto, tornando a sentença expressa pelo conector "SE" em fato improvável, confractual, que contradiz a condição da gramática normativa, pois a condicionalidade deveria ser verdadeira e consequentemente ter a oração principal como verdadeira.

Em comparação, com a retirada da marcação do conector "SE", o texto modificado:

\section{“A gente não pode ter tudo/ Qual seria a graça do mundo assim", passa-se a} estabelecer uma oração condicional que atende à oração principal, com uso da forma verbal no modo indicativo. Portanto, o professor iria quebrar a ideia fixa de que somente a conjunção caracteriza a condicionalidade na oração.

Na segunda atividade proposta, disposta no apêndice $B$, o gênero discursivo/textual é uma carta de cobrança, muito conhecida dos alunos. O reconhecimento do gênero e das 


\section{Revista do SELL}

v. 6 , no. 3

ISSN: $1983-3873$

funções deste tipo de texto contribui para a compreensão da semântica textual, juntamente com o estudo da condicionalidade no texto. Ou seja, além da reflexão do uso do conector "SE", nesta atividade o aluno precisa ser um leitor competente para perceber que a forma verbal empregada interfere na significação do texto. E, considerar ainda, na reescrita, que há outras formas de marcação pela conjunção, mas que elas não são idênticas semanticamente.

Finalmente, a terceira atividade, apêndice C, mobiliza a teoria de Neves e Perini. Pois, o professor deve mediar o conhecimento dos alunos para que eles percebam as alterações de efeito de sentido produzidas com os diferentes usos do conector "SE" nas sentenças. Os sentidos globais do texto explorados nos posts da rede social Instagram do personagem "Chapolim Colorado", estabelecem diferentes interpretações da condicionalidade, uma vez que a forma verbal muda significamente o dizer. Este verbo, associado à marcação do conector "SE", juntamente com as expressões não verbais, que provocam o humor, produzem condicionalidade em determinados momentos (figura 3), porém provoca condição improvável (figura 2), quando empregado com o imperfeito do subjuntivo ou apresenta uma problemática já resolvida (figura 4) ou introduz interrogativas indiretas (figura 1).

Pensa-se que com tais atividades, pode-se proporcionar uma discussão da língua em uso, e do que seria a condicionalidade, e, neste caso, estabelecida pelo conector SE. Visto que, deu-se atenção central aos sentidos de compreensão dos textos, focando os exercícios na construção pragmático-semântica estabelecida na leitura e na escrita. Assim sendo, acredita-se que houve mobilização dos saberes linguísticos: vernacular, descritivo/prescritivo e descritivo-teórico, possibilitando aos alunos uma reflexão sobre a língua. Conforme Bagno (2012, p. 170), "uma vez que a função primordial das línguas humanas é permitir a interação de seus falantes por meio da produção de sentidos, os recursos linguísticos se vinculam todos ao campo da semântica, que é precisamente o campo da significação[...]". 


\section{Revista do SELL}

v. 6 , no. 3

ISSN: $1983-3873$

\section{CONSIDERAÇÕES FINAIS}

Por meio do confronto das teorias acerca da tradição gramatical, com a tradição sociolinguística, o professor de Língua Portuguesa pode conduzir melhor os estudos dos conceitos gramaticais sobre a condicionalidade expressa ou não pelo conector SE. Conduzir o tema por meio de textos mais próximos da realidade do aluno contribui para despertar o seu interesse e para que possa perceber o uso de tais mecanismos nos textos que lê, ouve, escreve e fala.

A teoria acadêmica tem voltado seus esforços para a prática de sala de aula, portanto não é difícil acessar textos que possam ajudar o professor a ampliar o repertório apresentado pelo livro didático.

Defende-se que o ensino centrado no texto permite ao aluno a verificação das estruturas macroestruturais e microestruturais presentes no co-texto, e observar qual conector está sendo marcado ou não, qual sua função e forma de articulação na determinação da semântica textual é importante e esperado nas aulas de linguagens. Sabese que é possível, tanto para o professor quanto ao aluno, ir além das classificações das orações, dos exercícios de memorização dos nomes e das frases isoladas dos seus contextos.

Ao comparar a tradição gramatical e os estudos sociolinguísticos se esta propondo que nas aulas de línguas, os alunos sejam levados a aprender a reconhecer os processos que acontece quando fala, lê ou escreve. Mas, propor-se aulas reflexivas que possam contribuir com as habilidades de leitura e escrita dos alunos em processo de formação.

Finaliza-se defendendo que é necessário aliar os saberes linguísticos de uso do falante, aos saberes linguísticos gramaticais e ainda aos saberes linguísticos produzidos pelas correntes científicas. Levando para sala de aula esses confrontos e aliando um ao outro. Tem-se, por isso, o professor, como mediador do ensino, aquele que poderá minimizar as tantas lacunas existentes no ensino de Língua Portuguesa em nossas salas de aula. 


\section{REFERÊNCIAS}

ANTUNES, I. Gramática contextualizada: tirando o pó das ideias simples. São Paulo: Parábola Editorial, 2014.

BAGNO, M. Gramática pedagógica do português brasileiro. São Paulo: Parábola Editorial, 2012.

BARBOSA, A.G. Saberes gramaticais na escola. In.: VIEIRA, Sílvia Rodrigues; BRANDÃO, Sílvia Figueiredo (Orgs.). Ensino de gramática: descrição e uso. São Paulo: Contexto, 2011.

BARRETO, T.M.M. Gramaticalização das conjunções na história do Português. Tese de doutorado, UFBa. Salvador, 1999.

BECHARA, E. Moderna Gramática Portuguesa. 37.ed. Rio de Janeiro: Lucerna, 2010. p. 276-479.

BLING. Texto: Carta de Cobrança. Disponível em <https://www.bling.com.br/ manuais/imagens/ carta.cobranca.4.png>. Acesso em: 03.12.2016.

CEREJA, W. R, MAGALHÃES, T. C. Português linguagens, 9. ano. 9.ed. São Paulo: Saraiva, 2015.

CUNHA, C; CINTRA, L.F.L. Nova gramática do português contemporâneo. 5.ed. Rio de Janeiro: Lexikon, 2001.

MONTEIRO, Lemes, José. O Escopo da Sociolingüística. In: Para Compreender Labov. 2. ed. Petrópolis, RJ : Vozes, 2000.

NEVES, M.H.M. Gramática de usos do português. 2 ed. São Paulo: Editora Unesp, 2011.

PERINI, M.A. Gramática do português brasileiro. São Paulo: Parábola Editorial, 2010.

VILELA, A. Música: Trem Bala. Disponível em <https://www.vagalume.com.br/ana-

vilela/trem-bala.html> Acesso em: 03.12.2016.

@CHAPOLINOFICIAL. Posts Instagram. Disponível em

$<$ https://www.instagram.com/chapolinoficial> Acesso em: 01.12.2016. 
v. 6 , no. 3

ISSN: $1983-3873$

\section{APÊNDICES}

\section{APÊNDICE A - Atividade 1}

Professor, recomenda-se que a musicalidade seja explorada na sala de aula. Por isso, sugere-se que a canção seja ouvida, antes de qualquer trabalho reflexivo sobre a mesma.

Leia a letra da música "Trem-bala" da cantora e compositora Ana Vilela, que é de Londrina/PR. A canção "viralizou" pela rede social Whatsapp no segundo semestre de 2016, ficando conhecida pelos usuários da rede social.

\section{Música: Trem-bala}

Não é sobre ter

Todas as pessoas do mundo pra si

É sobre saber que em algum lugar

Alguém zela por ti

É sobre cantar e poder escutar

Mais do que a própria voz

É sobre dançar na chuva de vida

Que cai sobre nós

É saber se sentir infinito

Num universo tão vasto e bonito

É saber sonhar

E então fazer valer a pena cada verso

Daquele poema sobre acreditar

Não é sobre chegar no topo do mundo

Saber que venceu

É sobre escalar e sentir

Que o caminho te fortaleceu

É sobre ser abrigo

E também ter morada em outros corações

E assim ter amigos contigo

Em todas as situações

\section{A gente não pode ter tudo}

Qual seria a graca do mundo se fosse assim

Por isso eu prefiro sorrisos

E os presentes que a vida trouxe

Pra perto de mim

Não é sobre tudo que o seu dinheiro

É capaz de comprar

E sim sobre cada momento

Sorriso a se compartilhar 


\section{Revista do SELL}

v. 6 , no. 3

ISSN: $1983-3873$

Também não é sobre correr

Contra o tempo pra ter sempre mais

Porque quando menos se espera

A vida já ficou pra trás

Segura teu filho no colo

Sorria e abraça teus pais

Enquanto estão aqui

Que a vida é trem-bala parceiro

E a gente é só passageiro prestes a partir

Laiá, laiá, laiá, laiá, laiá

Laiá, laiá, laiá, laiá, laiá

Segura teu filho no colo

Sorria e abraça teus pais

Enquanto estão aqui

Que a vida é trem-bala parceiro

E a gente é só passageiro prestes a partir.

(Disponível em <https://www.vagalume.com.br/ana-vilela/trem-bala.html>. Acesso em: 03.12.2016).

Releia o trecho da canção em negrito, e, posteriormente, responda:

a) Como você entende este trecho? "A gente não pode ter tudo/ Qual seria a graça do mundo se fosse assim/ Por isso eu prefiro sorrisos/ E os presentes que a vida trouxe/ Pra perto de mim". O que ele diz?

b) Compare, agora, o texto destacado anteriormente com o novo texto "A gente não pode ter tudo/ Qual seria a graça do mundo assim/ Por isso eu prefiro sorrisos/ E os presentes que a vida trouxe/ Pra perto de mim". Houve mudança de sentido, em comparação ao texto original? Explique.

c) A condicionalidade do texto está na marcação pelo conector "SE"? Justifique sua resposta. 


\section{APÊNDICE B - Atividade 2}

Leia a carta de cobrança, abaixo:

$\begin{array}{ll} & \text { Adriel Cordazzo } \\ \text { Rua Getủlio Vargas, - Cidade Alta } \\ \text { Bento Gonçalves - RS - 95700-000 } \\ \text { Fone (54) } 8105-0143 \text { - E-mail adriel_cordazzo@hotmail.com } \\ \text { CNPJ 93.518.124/0001-44 - IE 0100052312 }\end{array}$

Bento Gonçalves, 11 de Setembro de 2014

Prezado(a) Senhor(a)

Lauren Cordazzo

Endereço Rua Getúlio Vargas, 98 Bairro Cidade Alta

CEP 95.700-000 Municipio Bento Gonçalves UF RS

Com nossos cordiais cumprimentos, informamos V.S. a que até a presente data não consta em nossos arquivos o(s) pagamento(s) da(s) contribuição(oes) abaixo relacionadas do corrente ano:

\begin{tabular}{|l|l|l|}
\hline Mès & Vencimento & Valor \\
\hline Setembro & $08 / 09 / 14$ & 10,00 * Valores sem correções \\
\hline Setembro & $10 / 09 / 14$ & 100,00 * Valores sem correções \\
\hline
\end{tabular}

Se por ventura já estiverem paga(s), queira por gentileza apresentar o comprovante do pagamento o mais breve possivel no setor Financeiro para que possamos atualizar nossos registros.

Atenciosamente

Departamento Financeiro

(Disponível em <https://www.bling.com.br/manuais/imagens/carta.cobranca.4.png>. Acesso em: 03.12.2016).

a) Qual a finalidade deste tipo de texto?

b) Agora, releia a sentença "Se por ventura já estiverem paga(s)[...]". Na construção de sentido, o trecho, passa que tipo de ideia? Explique com suas palavras.

c) A construção "Se por ventura já estivessem paga(s)[...]" seria adequado no texto acima? O modo verbal interfere na compreensão dos sentidos do texto?

d) Você conseguiria reescrever o trecho acima sem uso do "SE", sem alterar seu sentido? Escreva aqui como ficou seu texto. 


\section{APÊNDICE C - Atividade 3}

Observe os posts retirados de uma rede social, que são pequenos textos associados à imagem do "Chapolin Colorado" ${ }^{2}$, que tem como intenção produzir humor no leitor. Depois, faça o que se pede, refletindo sobre o sentido global de cada texto.

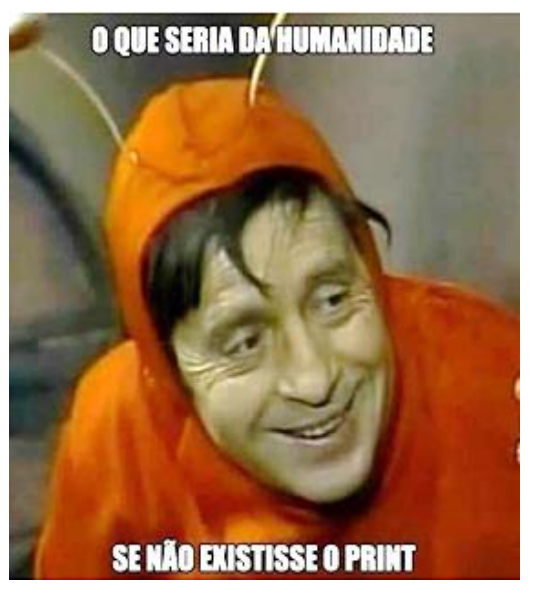

Figura 1

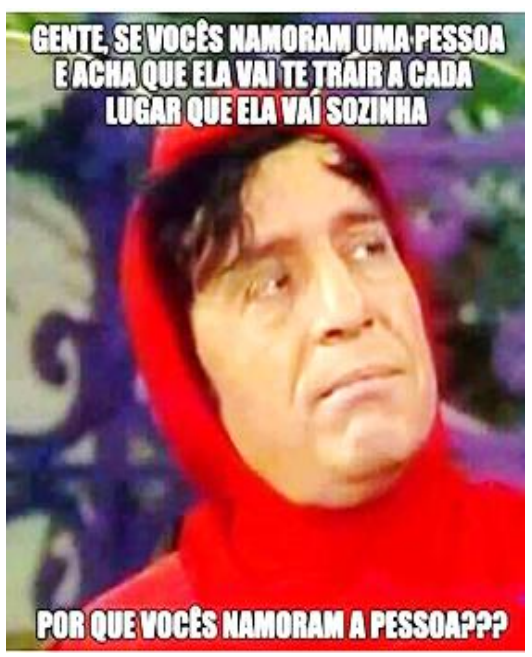

Figura 3

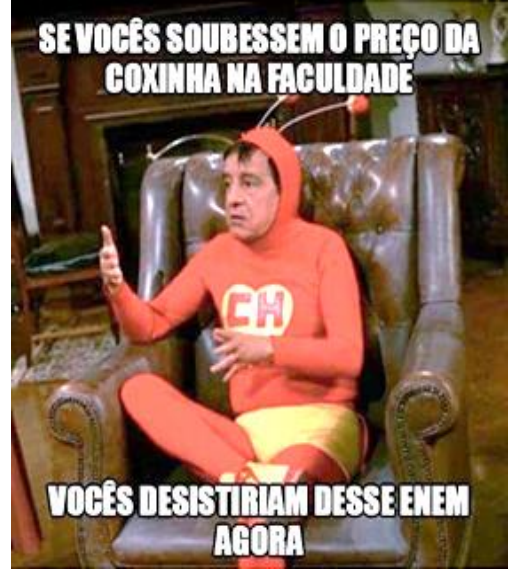

Figura 2

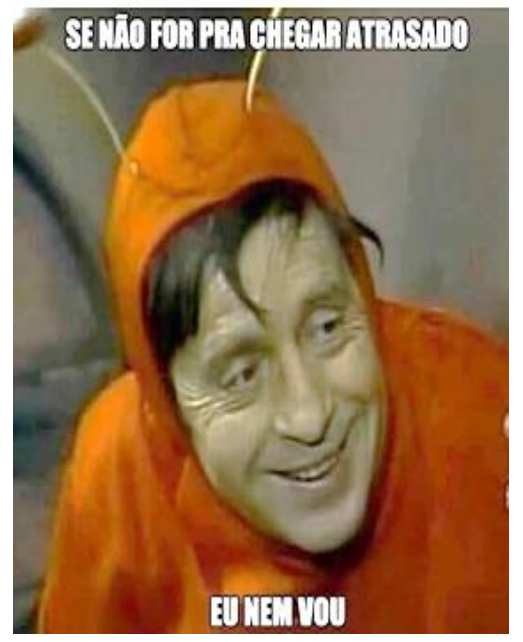

Figura 4

(Fonte: instagram. Disponível em: <https://www.instagram.com/chapolinoficial/>. Acesso em 03.12.2016)

\footnotetext{
2 @ chapolinoficial é um personagem da rede social Instagram, originado do programa de televisão mexicano Chapolin Colorado (no original Chapulín Colorado), também conhecido como Polegar Vermelho e Vermelhinho.Roberto BolañosChespiritoSegundo Bolaños, Chapolin foi criado para em forma de protesto contra os super-heróis enlatados norte-americanos: foi criado para mostrar a força acovardada da América Latina[...].
}

(Disponível em <http://pt-br.chaves.wikia.com/wiki/Chapolin_Colorado>. Acesso em: 03.12.2016) 
a) A figura 1 apresenta uma pergunta indireta com uso do conector "SE". Este texto está expressando uma condição, ou seja, a primeira, e, consequentemente, a segunda oração são verdadeiras? Explique.

b) A figura 2 traz uma hipótese com uso do verbo "soubessem", no modo subjuntivo, e a atitude proposta na segunda oração é improvável. Teremos em comparação à figura1, o mesmo efeito de sentido? Justifique.

c) Na figura 3, temos duas orações (namoram, vai te trair) que podem ser reais. Portanto, podemos dizer que as proposições são verdadeiras, de acordo com a gramática normativa. Mas, se eu tirasse o conector "se" da sentença, assim "Gente, vocês namoram uma pessoa e acha que ela vai te trair a cada lugar que ela vai sozinha", a condicionalidade não existiria mais?

d) Qual a problemática que é introduzida pelo conector "SE" na figura 4? Existe um fato a ser resolvido na sentença ou está implícito a afirmativa "Vou chegar atrasado de qualquer forma"? Justifique.

e) As imagens colaboram no entendimento do texto, na sua construção de sentido?

Reitera-se que não nos restringimos ao ensino da gramática normativa que classificaria os mesmos como condição estabelecida pela função do conector "se". 
APÊNDICE D - Comentários de alguns alunos sobre a intervenção didática

A partir da pergunta provocadora, "Comparando o estudo da condicional SE, apresentado pela proposta do livro-didático e a última aula, escreva seu ponto de vista sobre o assunto". Foi selecionado na sala, algumas respostas das impressões dos alunos sobre a proposta pedagógica aplicada.
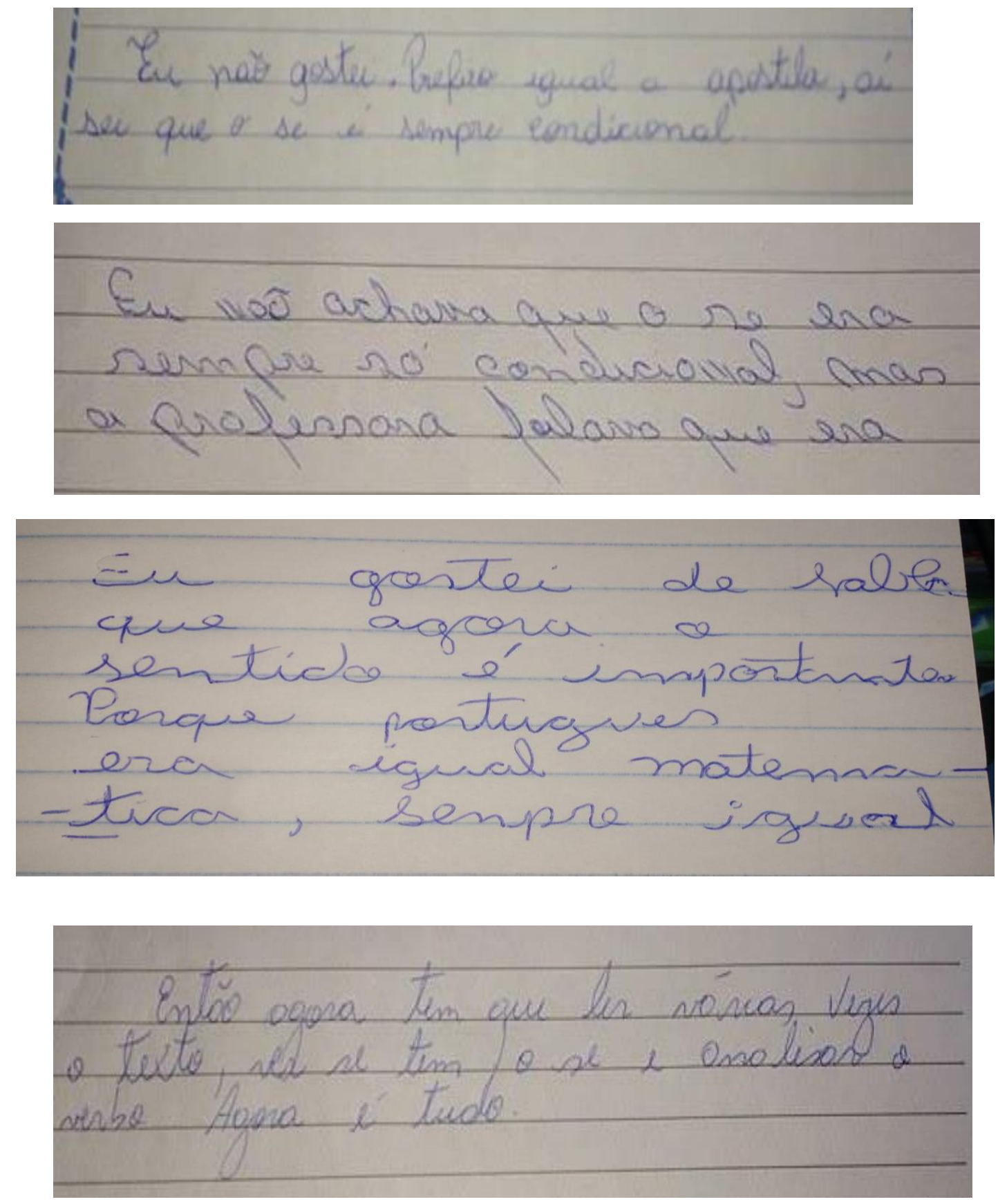